\title{
Pode a história imunizar as vacinas? Políticas de vacinação e suas imersões no cenário global
}

\author{
Can history immunize the vaccines? \\ Vaccination policies and their places in global scenario
}

\author{
Rodrigo Ramos Lima ${ }^{i}$ \\ ' Doutorando, Programa de Pós-graduação em História das Ciências e da Saúde/Casa de Oswaldo Cruz/Fiocruz. \\ Rio de Janeiro - RJ - Brasil \\ orcid.org/0000-0001-7652-735X \\ contatomagisterio@hotmail.com \\ Luiz Alves Araújo Netoi \\ ii Pós-doutorando, Programa de Pós-graduação em História das Ciências e da Saúde/Casa de Oswaldo Cruz/Fiocruz. \\ Rio de Janeiro - RJ - Brasil \\ orcid.org/0000-0001-7965-2957 \\ luizalvesan@hotmail.com
}

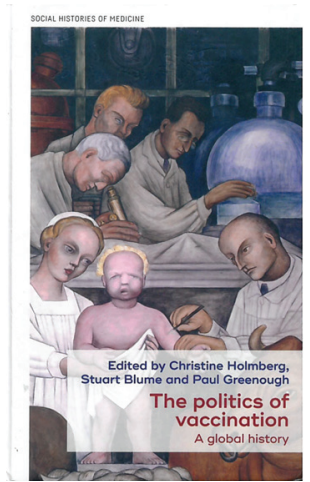

HOLMBERG, Christine; BLUME, Stuart; GREENOUGH, Paul (Ed.). The politics of vaccination: a global history. Manchester: Manchester University Press. 2017. 336p.

A literatura recente do campo da saúde tem se dedicado amplamente ao debate sobre a relação entre proposições que ganham o tom de "medidas globais" e as tensões referentes à aplicação de tais modelos em nível local. A ideia de que determinados agravos e temas podem ser pensados em termos de uma "saúde global" impõe a gestores, profissionais da ponta e pesquisadores reflexões sobre os limites da relação entre o aspecto local das práticas de saúde e suas conexões com outras instâncias. Nesse sentido, um ponto central parece emergir: como articular estratégias globais a contingências e caracteres locais? Ou melhor, quais os limites das políticas e práticas no contexto da saúde global? As perguntas são importantes em um momento no qual as vacinas estão no centro de críticas e ataques de grupos negacionistas, sobretudo religiosos. Ponderações eloquentes a esses questionamentos e ao negacionismo científico contemporâneo estão na base da coletânea The politics of vaccination: a global history, organizada por Christine Holmberg, Stuart Blume e Paul Greenough.

O livro é dividido em três partes temáticas e prioriza estudos que versam sobre as décadas de 1950 em diante, abrangendo, assim, experiências de regiões pertencentes a Ásia Oriental, África Ocidental, Américas e Europa. A primeira seção, "Vaccination and national identity", acompanha políticas de vacinação e sua contribuição para o fortalecimento das identidades nacionais. Nela se destacam três estudos. Paul Grennough investiga a contribuição do combate à varíola no Paquistão Oriental em 1958, durante a Guerra Fria, para o modelo de erradicação global da doença. Em seguida, Niels

http://dx.doi.org/10.1590/S0104-59702020000300015 
Brimnes contextualiza os movimentos de oposição à campanha contra tuberculose (BCG) na Índia nos anos seguintes à independência. Posteriormente, Dora Vargha Examina a ação dos Estados comunistas da Europa Oriental e aponta como o combate contra a poliomielite na Hungria, em 1959, serviu de inspiração à OMS, no ano seguinte.

No segundo segmento, "Nationality, vaccine production and the end of sovereign manufacture", o leitor acompanha os tempos iniciais das produções de imunoterápicos desempenhadas por laboratórios estatais e os anos de forte concorrência no fornecimento de vacinas por empresas estrangeiras, em nível nacional e no âmbito privado, entre final do século XIX e começo do século XX. Cumpre destacar a alentada averiguação dessa seção sobre as inflexões ocasionadas pelo neoliberalismo no processo de erosão dos sistemas de fornecimentos de imunizantes por aparelhos estatais, enfraquecidos a partir de 1980. Um contraste instigante a esse triste cenário emerge no estudo que trata da excepcionalidade do Brasil no campo da produção de imunoterápicos. Jaime Benchimol, ao explorar a tradição de cientistas brasileiros na busca da elaboração de vacinas contra a febre amarela, durante o século XX, historiciza as principais ações do Instituto Oswaldo Cruz no campo da medicina tropical nos anos 1930 e salienta as inovações em pesquisas com vacinas realizadas entre a Bio-Manguinhos e o plano das cooperação com institutos de pesquisas transnacionais, expondo, assim, a atuação recente da Fundação Oswaldo Cruz na produção de vacinas e demais agentes terapêuticos para o Sistema Único de Saúde (SUS) brasileiro.

A terceira parte, "Vaccination, the individual and society", visa expor a participação de meios de comunicação de massa na divulgação de notícias que causaram debates polêmicos, influenciando, desse modo, o surgimento de movimentos antivacínicos, bem como discute a participação dos indivíduos na adesão às campanhas de imunização, como expressão de solidariedade e reconhecimento da imunidade coletiva. Andrea Stöckl e Anna Smajdor abordam histórias de desconfianças frente às vacinas e abrem as reflexões sobre o caso do Reino Unido (1998-2003), a partir dos debates públicos suscitados pela campanha da vacina tríplice contra sarampo, caxumba e rubéola, bem como das polêmicas sobre a não confissão da vacinação do filho do primeiro-ministro britânico, Tony Blair. Na sequência, Britta Lundgren e Martin Holmberg focalizam a produção de vacinas contra a influenza e enfatizam a pandemia de influenza A (H1N1) na Suécia em 2009. Outrossim, analisam reportagens divulgadas sobre crianças e adolescentes acometidos por narcolepsia após a imunização, discutindo, por conseguinte, os depoimentos de familiares e as responsabilidades de jornais e websites na disseminação de pesquisas com considerável descrédito na comunidade internacional de especialistas. Posteriormente, Elisha Renne esquadrinha o caso da Nigéria, dos tempos coloniais aos idos de 2015 , abordando as resistências a vacinações contra a poliomielite, encaradas como novas ferramentas de colonização por líderes muçulmanos, professores universitários e profissionais da saúde. Por fim, William Muraskin encerra o livro com exposição crítica sobre as relações de poder em torno das lideranças internacionais em saúde pública dos séculos XX e XXI, e uma reflexão sobre o descrédito dos projetos de erradicação global de doenças infecciosas, com base em sistemas verticais de vacinação que nem sempre coadunam com as necessidades dos países em desenvolvimento.

Finalmente, a coletânea levanta, em suas ausências e presenças, um importante problema de fundo, relacionado à execução de programas de vacinação e aos modelos de atuação 
em saúde possíveis em meio às assimetrias globais. A realização de ações de imunização, descoladas do desenvolvimento de políticas mais amplas de atenção primária, contrapõe um modelo horizontal de saúde com a realidade de programas verticais. De modo similar, o silêncio das experiências dos usuários e de sua participação na realização (ou não) dos programas mostra como é necessária uma visão crítica da saúde global (Biehl, Petryna, 2013), atenta à difícil relação entre as políticas e a dimensão individual da saúde. Nessa perspectiva, o livro conscientiza sobre o papel das histórias das vacinas e sua capacidade em despertar no debate público nacional e global diferentes formas de luta contínua em defesa das ciências e das vidas. Além disso, é uma importante contribuição à compreensão do papel fundamental das campanhas de imunização na efetivação de políticas de prevenção e do funcionamento dos sistemas de saúde.

\section{REFERÊNCIAS}

BIEHL, João; PETRYNA, Adriana. When people come first: critical studies on global health. Oxford: Oxford University Press. 2013.
HOLMBERG, Christine; BLUME, Stuart; GREENOUGH, Paul (Ed.).

The politics of vaccination: a global history.

Manchester: Manchester University Press. 2017. 